\title{
Lenguajes estéticos para el cultivo de la memoria
}

\author{
Belén Vila \\ belen666333@hotmail.com
}

\section{Resumen}

La narrativa literaria de Alonso Cueto, el relato icónico de Yuyanapaq, el cómic Rupay, el Informe Final de la Comisión de la Verdad y Reconciliación como aquellos soportes artísticos que elaboran Hebert Rodríguez o Ricardo Wiesse interceptan las esferas sociales y políticas. Este artículo vincula esas complejas comunicaciones significativas, en tanto se comprendan las representaciones culturales y se traduzcan como una necesidad de expresión de una comunidad o de una nación. Por ende, desde ese lugar, se manifiestan y evocan. En ese sentido, repasa indirectamente la violencia política vivida en Perú, durante el período de opresión política en la época de Alberto Fujimori, Sendero Luminoso y el Movimiento Revolucionario Túpac Amaru. Este artículo profundiza sobre conceptos antropológicos vinculados a la memoria como actividad liberadora y el recuerdo como un proceso subjetivo y colectivo que interacciona con los aparatos simbólicos que se manifestaron en la sociedad peruana después del conflicto nacional dado entre 1980 y 2000. Concluye que los lenguajes estéticos logran activar la reflexión siempre y cuando los ciudadanos y las ciudadanas conozcan el pasado reciente y/o tardío. Y de esa forma alcancen a transmitirlo, ya que muchas generaciones adolecen de una cultura de la representación. Por tanto, es necesario generar tempranamente el hábito hacia el modo de poseer el conocimiento en la sociedad contemporánea.

Palabras clave: antropología cultural, memoria, artefacto estético, sociedad, política
Abstract
Alonso Cueto's literary narrative, the iconic story of Yuyanapaq, the comic Rupay, the Final Report of the Truth and Reconciliation Commission as those artistic media produced by Hebert Rodríguez or Ricardo Wiesse intercept the social and political spheres. This article 
links these complex meaningful communications, insofar as cultural representations are understood and translated as a need for the expression of a community or a nation. So, from there, they manifest and evoke. In this sense, it indirectly reviews the political violence experienced in Peru, during the period of political oppression in Alberto Fujimori, Sendero Luminoso and the Tupac Amaru Revolutionary Movement's era. This article delves into anthropological concepts linked to memory as a liberating activity and memory as a subjective and collective process that interacts with the symbolic apparatuses that manifested themselves in Peruvian society after the national conflict between 1980 and 2000. Concludes the aesthetic languages they manage to activate the reflection as long as the citizens know the recent or late past. They could transmit it, while many generations suffer a culture of representation. Therefore, it is necessary to generate early the habit towards the way of possessing knowledge in contemporary society.

Keywords: cultural anthropology, memory, aesthetic artifact, society, politics

\section{Pórtico para una lectura antropológica ${ }^{1}$}

Sin memoria nos manipulan ${ }^{2}$ Herbert Rodríguez

Los artistas se expresan desde distintos estilos y soportes $;^{3}$ a partir de esos registros, la sociedad toma nota, los activa y evoca al recuerdo, porque, por más bellos, buenos y verdaderos $^{4}$ (considerando la tríada platónica) que sean, nada dicen por sí mismos. La comprensión deviene, como indica Pierre Bourdieu, en el encuentro del observador competente o cultivado con la obra percibida. ${ }^{5}$

1 Este artículo reformula y amplía algunos conceptos antropológicos culturales, trabajados en aula, durante el primer módulo del Programa de Doctorado en Humanidades — que actualmente curso- de la Universidad de Piura (Campus Lima).

2 El epígrafe forma parte del conjunto de la obra muralista del artista Herbert Rodríguez. Se explica en detalle más adelante. La imagen está disponible en http://dosis.pe/wp-content/uploads/2017/02/arte-herbertrodrg-1.jpg (Acceso 24de marzo de 2017).

3 Literarios, fotográficos, gráficos, performativos, etc.

4 Con respecto a lo "verdadero", debe tenerse en cuenta el sistema de creencias, valores, subjetividades con las que crece el sujeto que se ubica en un tiempo y espacio geopolítico determinado; que es influenciado por lo social, por las experiencias cotidianas que lo delimitan.

5 Pierre Bourdieu, "Elementos de una teoría sociológica de la percepción artística", en Sociología del arte, dir. José Sazbón, 43-80 (Buenos Aires: Nueva Visión, 1971), 44. 
De tal estado de situación, se desprende la tesis de este documento, que analiza las representaciones culturales que instalan los productores desde diferentes asideros estéticos y que además actúan como dispositivos simbólicos que activan la memoria y evocan al recuerdo de los años 1980-2000, época de extrema violencia que padeció la sociedad peruana. Significa repensar no solo la lucha armada entre el Estado y Sendero Luminoso, sino el sitio que ocupa la memoria por medio de los actuales y nacionales aparatos estéticos que se manifiestan como modos de "decir" y evocan desde ese lugar. Desde sus múltiples dimensiones, los orfebres estéticos remueven la memoria a partir de la obra de arte, que "como todo objeto cultural, puede ofrecer significaciones de niveles diferentes" jerarquizados por el significante que pretende transmitir. Con la creación de piezas nuevas, mantienen el significado primigenio, pero, a la vez, lo resignifican, se nutren los espacios olvidados por el pensamiento «líquido», ${ }^{7}$ lo cargan de valores subjetivos y lo derivan nuevamente al pasado. Parafraseando a Bourdieau esa necesidad de apropiarse de valoraciones culturales aparece en aquellos cuya formación familiar, escolar les ha indicado cómo deben apropiarse de aquellos bienes culturales. ${ }^{8}$

Fernando Sellés, con un mensaje alentador, expone en ¿Cultura o culturalismo? que, si bien lo cultural "es todo aquello que produce el hombre con su trabajo [...], el hombre no se reduce a la cultura. Si eso fuera así, el hombre, cada quién, sería un producto de sus propias manos"9 y prosigue en Antropología cultural, filosófica y trascendental, dado que es el hombre "el que inventa la cultura, no la cultura la que genera al hombre. De modo que es el hombre el que está llamado a dotar de sentido a la cultura y no al revés". ${ }^{10}$ No es poco afirmar que en las $\operatorname{manos}^{11} \mathrm{y}$ en el pensamiento humano se origina la posibilidad de consolidar un plexo creador que interacciona con las intersubjetividades del elemento social, pues la sociedad y la cultura son construidas y a la vez construyen un tipo de hombres y mujeres que

6 Bourdieu, "Elementos de una teoría sociológica", 49.

7 Zygmunt Bauman, en La modernidad líquida, contrapone el estado líquido — por su fluidez-a la estabilidad —estado sólido-. Este juego lo amplía y desarrolla a lo largo del libro. La liquidez es sinónimo de lo light, que se utiliza como representación metafórica para referirse a la modernidad actual y contraponerla a la época anterior que era estable y no superficial.

8 Cfr. Bourdieu, "Elementos de una teoría sociológica", 61-2.

9 Juan Fernando Sellés, “Cultura o culturalismo?”, en Antropología para inconformes, Juan Fernando Sellés, 466-71 (Madrid: Rialp, 2005).

10 Juan Fernando Sellés, "Antropología cultural, filosófica y trascendental”, en Antropología para inconformes, Juan Sellés, 170-208 (Madrid: Rialp, 2006).

11 Se destaca la importancia de que la "mano" del hombre/mujer — en el sentido aristotélico, techné- cumple una función práctica; esto es, el ser humano manifiesta su realidad y sus relaciones con el espacio y tiempo, mediante las operaciones que ella realiza. 
se superan a sí mismos gracias a la comunicación, en el amplio sentido de la palabra. Por ejemplo, en la lengua de señas - a la que recurren generalmente las personas con discapacidad auditiva—, se necesita no solo de la gramática, sino de algunos movimientos del cuerpo, sobre todo del torso, de las variadas expresiones faciales, de la motricidad manual, de todas esas coordinaciones que ayudan a completar el sentido total del enunciado. En tanto, para emitir un juicio, una opinión, una idea, la comunicación es la que permite ese intercambio.

La ayuda esencial la brinda el sistema biológico y sus aparatos, el sonido — del que habla Aristóteles-, la lengua, que "sirve también para articular voces, es un órgano al que se le ha añadido una función más [...] masticadora y gustativa [...] es extraordinariamente apta para hablar". ${ }^{12}$ Leonardo Polo considera que las funciones entre labios, dientes y lengua aumentan a medida que se efectúan distintos movimientos y operaciones al pronunciar un sonido. A propósito, ve en el lenguaje características propias "no lo dice todo, ni puede decirlo todo"13 y esta peculiaridad se desplaza a las representaciones simbólicas que forman parte de la continuidad de las palabras. Así Charles Baudelaire lo hace saber y lo transcribe poéticamente en el célebre soneto Correspondencias.

Es el ser humano el que tiene "carácter creador" y al que le corresponde "cultivarlo", porque "al cultivarlo añade, continúa el mundo, y así aparece algo nuevo, no precontenido. Eso es la cultura y lo simbólico".14

A continuación, se ofrece un recorrido desde lo simbólico, se atiende al lenguaje de las formas estéticas, arte, literatura, narración iconográfica, documentos históricos narrativos y visuales difundidos en distintos soportes, que desde sus diversos canales enuncian significados que buscan encontrarse con el "tú" para "decir”. Y cuando lo encuentra, ¡vaya si expresan!

\section{El lenguaje de los aparatos estéticos}

El lenguaje de los aparatos estéticos monta el aparato "de una cultura refinada, [...] consagra el triunfo de la divinidad o del príncipe, [responde a la idea de] hacer compartir un imaginario a las multitudes y a las culturas heterogéneas", ${ }^{15}$ gozan de una perennidad de

12 Leonardo Polo, Quién es el hombre: Un espíritu en el tiempo (Madrid: Rialp, 1996), 3.

13 Ibid., 7.

14 Ibid, 7-8.

15 Ibid., 147-8. 
representación casi contradictoria porque el hermetismo del símbolo lo hace inaccesible a las comunidades menos entendidas, indica Sergio Gruzsinsky. En efecto, como el lenguaje artístico es también manifestación de la cultura, con mensajes desestructurados, los comunicadores interceptan la historia, salen a su cruce y manifiestan el estado en que se encuentra su intimidad. Dado que el ser humano "es más que naturaleza; es espíritu [el hombre y la mujer continúan a la naturaleza, crean, cultivan cultura, que es el] añadido humano a las cosas [...], es también una continuación". ${ }^{16}$ En este sentido, Herbert Rodríguez comunica su propósito mediante la Línea de tiempo de Memoria Crítica,${ }^{17}$ donde relata, desde el arte crítico, los sucesos que se vivieron en Perú desde 1979 a 2016. Repasa las violaciones a los derechos humanos cometidas por Sendero Luminoso, ${ }^{18}$ muestra el arte alternativo en Lima, registra mediante fotografías y titulares de prensa la dinámica social, cultural y política del país. Estos archivos forman parte de los fragmentos que componen el recuerdo. Así, la larga línea histórica da cuenta de los sucesos que acaecen en un tiempo y en un espacio. A veces, se los percibe separados unos de otros, con más espacios entre ellos; en otras circunstancias se muestran apiñados y cercanos, casi sobrepuestos. Así, las remembranzas se presentan en la memoria individual o colectiva, y aunque se pase raya a los recuerdos, estos siguen sangrando. La actitud de este artista no es la vía de escape, no busca elevarse, ni aislarse, sino todo lo contrario, permanecer comunicado con el "otro" por medio del mensaje.

Se compone el concepto "memoria" a partir de las glosas que proponen Paul Ricoeur y Susan Buck Mors. Es la herramienta que brinda el acceso al pasado; por ende, activa el recuerdo (que es pasivo, porque es activado) ausente en el presente "quedando implícita la referencia al pasado". ${ }^{19}$ Ese pasado es lo vivido, lo sentido, sin embargo, lo que se percibe en el presente es su "mímesis", que implica semejanza más no originalidad, comporta distancia en un tiempo (un antes y un después). A este concepto griego Susan Bocks agrega el sustantivo "anestésica" que denota la falta de sentido, juego que propone como oposición a

16 Ibid, 9-11.

17 Ver enlace cedido por el artista plástico Hebert Rodríguez especialmente para este documento: http://controversiarte.blogspot.pe/2016/07/arte-para-que-exposicion-manifiesto_85.html. Acceso 26 de octubre de 2017.

18 El Partido Comunista del Perú - Sendero Luminoso tiene como misión cambiar todos los instrumentos estatales de poder y sustituirlos por un régimen idealista que garantice la igualdad de todos los sectores sociales. Para conseguir sus objetivos, inculcó como políticas el odio hacia los que pensaban diferente y la violencia extrema en contra de la población policial, militar, civil (niñas, niños, mujeres embarazadas, hombres) que no acataban su doctrina maoísta. 
todo aquello que sí lo tiene. ${ }^{20}$ Ahora bien, desde la política sociológica de Pierre Bourdieu, se califica a la "aistkesis" como una de las formas extremas del placer "que acompaña la percepción estética [pero que también la reduce al deleite] obtenido por la degustación erudita y que supone, como condición necesaria, aunque no suficiente, el desciframiento adecuado". ${ }^{21}$ Desde ese campo, la obra, como elemento simbólico, solo existe para quien la descifra. ${ }^{22}$

La "alienación sensorial yace en el origen de la estetización de la política"23 en la época moderna. No se trata solo de memoria racional, sino de todo el cuerpo. Sin los sentidos, el arte se encamina a la destrucción. Por medio de la percepción, los sentidos proclaman la autopreservación, ya que son el "núcleo de resistencia a la domesticación cultural [...] tanto del individuo como del grupo social". 24

La obra, en su conjunto, también como recepción artística, expresa la importante tarea de responsabilidad que le compete al arte. Conlleva el acopio de la documentación, su ulterior propagación al registrar las expresiones más sobresalientes del pasado colectivo de una nación. Por su parte, Mario Benedetti señala en Ese gran simulacro, que "el olvido está lleno de memoria/ que a veces no caben las remembranzas/ y hay que tirar rencores por la borda// en el fondo el olvido es un gran simulacro/ nadie sabe ni puede — aunque quiera — olvidar". ${ }^{25}$

Desde la perspectiva literaria del escritor de novelas con temáticas de violencia política Alonso Cueto (Lima, 1954) contribuye a activar la memoria con la creación de la trilogía de La hora azul (2005), La pasajera (2015), La viajera del viento (2016). Estas narracciones ahondan en espacios de muerte y terror. Estos tópicos se expanden en todos los ámbitos del territorio nacional, pero recaen con más fuerza, como magma negro, sobre algunas lateralidades geográficas. Al respecto, Michel Taussing denomina "space of dead" a aquellos lugares amplios, cuyas amplitudes ofrecen posiciones de avance así como de extinción: "The space of deadth is crucial to the creation of meaning and consciousness, nowhere more so than in societies where torture is endemic and where the culture of terror flourishes". 26 "El espacio de la muerte es crucial para la creación de significado entre sentido y conciencia, en ninguna parte más que en las sociedades donde la tortura es endémica y en donde florece la cultura del terror" (Traducción propia)

20 Susan Buck, "Estética y anestésica: Una reconsideración del ensayo sobre la obra de arte en Walter Benjamin” (1993),

55-98. http://www.academia.edu/10504242/Est\%C3\%A9tica_y_anest\%C3\%A9tica._Una_revisi\%C3\%B3n_del_e nsayo_de_W.Benjamin_sobre_la_obra_de_arte.

21 Bourdieu, "Elementos de una teoría sociológica", 51.

22 Ibid., 52.

$231993,57$.

24 Ibid., 59.

25 Mario Benedetti, "En el gran simulacro", en El olvido está lleno de memoria, Mario Benedetti, 13 (Buenos Aires: Sudamericana, 2000), 13.

26 Michael Taussig, "Culture of Terror- Space of Death. Roger Casement's Putumayo Report and the Explanation of Torture”, Comparative Studies in Society and History 26 n. ${ }^{\circ} 3$ (julio de 1984): 486. 
Y florece no solo en la realidad, sino en la ficción, ya que la provincia de Ayacucho es el espacio real, pero también imaginario, donde se depositan las imágenes de lo macabro que gravitan en torno a La hora azul. Si bien la historia de la novela corta se remonta a un período de pacificación y lejos queda del escenario de batalla del Estado peruano con el grupo terrorista ${ }^{27}$ Sendero Luminoso, el recuerdo del pasado atrae las escenas de horror, al presente. Aunque esté lejano el período bélico, no se atenúan las secuelas y las huellas que ha dejado el conflicto estatal. La narración versa sobre la historia de Miriam, una ayacuchana joven, bonita e indefensa, a la que los militares le matan la familia. Luego, la secuestran y la llevan al "Fuerte militar" para gozo y disfrute sexual del comandante Ormache. Es Adrián Ormache hijo del jefe militar - quien decide ir en la búsqueda de Miriam a partir de un pedido balbuceante, casi indescifrable que le hace su progenitor antes de morir. Este hecho azuza la memoria "un fenómeno siempre actual, [...] afectiva y mágica", y lo espolea para que se reconcilie con el pasado, el "ayer". ${ }^{28}$ Adrián "se nutre de recuerdos borrosos, empalmados, globales o flotantes, particulares o simbólicos" 29 que se desempañan cuando el dato real asevera que el hijo de Miriam es su hermano.

La narrativa esboza el contrapunteo entre el conquistador y lo conquistado y enseña que el espacio de la muerte "is preeminently a space of transformation: through the experience of deadth, life; through fear, loss of self and conformity to a new reality". ${ }^{30}$

“es preminente un espacio de transformación: a través de la experiencia de la muerte, la vida; a través del miedo, la pérdida de uno mismo y la conformidad con una nueva realidad" (traducción propia)

La otra novela, denominada La pasajera, recorre el drama exterior, pero sobre todo el interior, de aquellos seres que sobreviven física pero no psicológicamente. Los personajes protagonistas, Arturo y Delia, dejaron Ayacucho atrás; ahora intentan reconstruir sus vidas, pretenden ser libres. De hecho, lo son, pero no plenamente: si bien intentan añadir elementos positivos a sus vidas para no retraerse, cargan la culpa y añoran el perdón. Al respecto, Hannah Arendt introduce la tesis de que perdonar es útil para "deshacer los actos del pasado,

27 La Real Academia Española define "terrorismo" a la "sucesión de actos de violencia ejecutados para infundir terror"; otra de sus acepciones se refiere a la "actuación criminal de bandas organizadas, que, reiteradamente y de modo indiscriminado, pretende crear alarma social con fines políticos".

28 Pierre Nora, Les lieux de mémoire (Montevideo: Trilce, 2008), 21.

29 Ibid.

30 Taussig, "Culture of Terror", 498. 
cuyos 'pecados' cuelgan como la espada de Damocles sobre cada nueva generación". ${ }^{31}$ Lo peor es que, tanto el perdón como la honra, necesitan del elemento social, de la "actuación de los otros", ${ }^{32}$ de ser honrados con el perdón de los demás.

Como confirma Michel Taussing, "most of the evidence comes through stories". 33

"La mayoría de la evidencia proviene de historias" (traducción propia)

Así, la trilogía Redención ${ }^{34}$ se cierra con La viajera del viento, novela que hace dialogar el pasado con el presente, pero no precisamente para reconciliarse, sino para redimirse. Al fin y al cabo, las narrativas "son en sí mismas evidencia del proceso por el cual una cultura de terror fue creada y sostenida" (traducción propia) "are in themselves evidence of the process whereby a culture of terror was created and sustained". ${ }^{35}$ Ángel, el principal personaje masculino, irá preso, perderá su condición de libertad por voluntad propia, decide flagelarse y autocastigarse, porque siente que, de esa manera, paga con la cárcel lo que hizo. En general, el lenguaje empleado por Cueto se mueve dentro de la ficción literaria aunque le hace un guiño a la historia. El mensaje es indirecto debido a que "se realiza por medio de metáforas, símbolos" ${ }^{36}$ que se convierten en algo que va más allá del texto, y que es trascendental, "no solo porque él [el símbolo] es detector de la realidad humana, sino también porque una filosofía iluminada por los símbolos puede pretender la "transformación cualitativa de la conciencia". 37

31 Hannah Arendt, La condición humana (Buenos Aires: Paidós, 2009), 256.

32 Ibid., 257.

33 Taussig, "Culture of Terror", 482.

34 Redención, para la Real Academia Española, es “la acción y el efecto de redimir”. En la segunda acepción refiere a "la redención que Jesucristo hizo del género humano por medio de su pasión y muerte". La trilogía redime a las víctimas.

35 Taussig, "Culture of Terror", 482.

36 Paul Ricoeur. Tiempo y narración I. México: Siglo XXI, 2004, 15.

37 Ibid., 15-6. 
La memoria "se enraíza en lo concreto, el espacio, el gesto, la imagen y el objeto"; 38 por ello debe ser profundo, así, el Informe final de la Comisión de la Verdad y Reconciliación de Perú se desarrolla en nueve tomos.

La comisión estuvo presidida por Salomón Lerner e integrada por Monseñor José Antúnez de Mayolo, Humberto Lay, Beatriz Alva Hart, Sofía Mcher, Carlos Iván Degregori, Carlos Tapia, Luis Arias, entre otros. Se llevó a cabo durante el gobierno provisional de Valentín Paniagua, y cumplió con un proceso de sistematización de la documentación; es decir, enumeró los factores que hicieron posible la violencia. Se adicionaron algunos de los apuntes de los investigadores que fueron reclutados durante su labor de campo, que describen las horribles situaciones que padecieron las víctimas. Estos registros provienen de fuentes orales; así se explicita en la introducción del informe. Entre otras fuentes documentadas, se da cuenta de las audiencias públicas de casos, conversaciones grupales que son templadas por un moderador que solo expone la temática más no participa del diálogo de los participantes, entrevistas con diferentes formatos, construidas cara a cara con el entrevistado, donde se presentan interrogantes abiertas. Aparecen interrelaciones con testimonios directos (víctimas y victimarios) de la violencia armada que se reproducen en entrecomillados. Es significativa la labor metodológica que se inscribe desde los talleres, donde los informantes, junto a los talleristas, proponen un espacio de encuentro con temáticas afines, dialogan y proponen finalmente balances. Para Vich, el trabajo referido recientemente continuó abriendo heridas y la historia es conocida: los partidos políticos fueron absolutamente incapaces de reconocer su responsabilidad en los hechos [...]. Pero, al mismo tiempo, la necesidad de recordar sigue estando muy presente y por ello [...] se han construido ya varios lugares de la memoria en el país. ${ }^{39}$

Yuyanapaq es el nombre de un conjunto icónico que recopila la historia del conflicto bajo las metáforas de la necesidad, el miedo, la injusticia, desplegados en todos los ámbitos físicos del hombre. Aquí, su trascendencia radica en la miseria. Como creación y recepción artística, la fotografía adquiere valor histórico al congelar una escena. Así, Walter Benjamin indica que, por su significación oculta, son piezas probatorias ${ }^{40}$ del período de opresión política que vivió Perú en la época de Fujimori, Sendero Luminoso y el Movimiento Revolucionario Túpac Amaru. Pues, Yuyanapaq se convierte en un arma de lucha contra el poder dominante, recoge figuras, recorta y fragmenta la historia, mostrando los resabios de la

38 Nora, Les lieux de mémoire, 21.

39 Víctor Vich, Poéticas del duelo (Lima: IEP, 2015), 11-2.

40 Walter Benjamin, La obra de arte en la época de su reproductibilidad técnica (CDMX: Ítaca, 2003), 59. 
guerra interna peruana. Dispone a lo largo del muestrario en diferentes imágenes — muchas en blanco y negro - los rostros de las víctimas, ahora emancipados, que padecieron los dañinos extremos del conflicto armado. La imagen identificada en el álbum con el número 101, corresponde a los "campesinos de Huaraccopata", ${ }^{41}$ una agrupación de moradores que se encuentran en las alturas de Huamanga, en Ayacucho. El pie de página del documento expresa que esta comunidad, regresa a su tierra de manera voluntaria, precisamente en 1996, 11 años después. De lejos, la imagen presenta trazos comparables con las técnicas impresionistas de Claude Monet o aquellos óleos posimpresionistas de Van Gogh — Green Wheat Field with Cypress - esto es, un conjunto de líneas entrecortadas que comunican. En esa apertura permite encontrar el "sistema sinestésico" del que habla Susan Bucks que consiste en que el sujeto capte desde otro lugar, ya no desde la intelectualidad sino desde la sensación que no es otra cosa que "estética". Porque en él se encuentran las percepciones sensoriales exteriores con las imágenes interiores de la memoria. ${ }^{42}$ El óleo se continúa en la realidad "que es el ámbito original" de la estética. ${ }^{43}$

Las líneas de la casa (en la fotografía) configuran un inicial esqueleto, los muebles inexistentes se conciben entre pajas, canastos (que guardan los alimentos), la calefacción durante las heladas nocturnas la brindarán las mantas. A lo lejos, el ganado, otras personas, símbolo de que la vida continúa pero por sobre todo puede volver a empezar. La familia vuelve al origen; a pesar de tantos años afuera, deciden retornar. Muestran el sentido de pertenencia, se han ido de ese lugar forzosamente obligados, como tantas otras familias desplazadas. Ellos han apostado a la génesis primitiva — porque en la vida es común "morir" y volver a empezar - no han olvidado de dónde partieron y no han podido quedarse en otro sitio, vuelven para recuperar la identidad (que incluyen los valores tradicionales religiosos, comportamientos, mitos, ritos colectivos, apego por el terruño e identificación con la lengua quechua, con un grupo humano) y con ella la posibilidad de esperanza. En definitiva, esta familia se salva, porque el amor los trasciende.

Otro dispositivo simbólico es el que realizó Ricardo Wiesse, artista plástico, en la quebrada de Cieneguilla. En memoria de los restos de nueve estudiantes y un profesor fueron desaparecidos por el comando del grupo Colina ${ }^{44}(2015,61)$ - que estaban vinculados

41 Ver anexo, fig. 3, tomada del álbum virtual de Yuyanapaq. http://idehpucp.pucp.edu.pe/yuyanapaq/.

42 Buck, "Estética y anestésica", 64-8.

43 Ibid., 58.

44 El Grupo Colina fue un grupo paramilitar, un "nuevo plan [...] para parar de una vez al terrorismo. [...]. Era una política de Estado [...] un grupo operativo, en eso consiste una guerra de baja intensidad, en armar 
académicamente a la Universidad Nacional de Educación de Enrique Guzmán y Valle, más conocida por La cantuta, flor sagrada de los incas en el período prehispánico. En los alrededores de la universidad crecen estas flores, de ahí su apodo. Wiesse, artista plástico, lleva a cabo una propuesta cultural. ${ }^{45}$

El investigador Víctor $\operatorname{Vich}^{46}$ (Lima, 1970) relata que el "proyecto consistió en pintar diez cantutas junto al sitio de las fosas clandestinas. Se utilizó un molde de cartón y polvo rojo de tintes naturales; [estas flores] neutralizan una profanación y sacralizan las vidas degradadas por el poder". ${ }^{47}$ Se antepone, "a la brutalidad del Estado, el giro estético" que pretende una "respuesta política". ${ }^{48}$ En definitiva, estos aparatos culturales rinden "homenaje a los muertos, [hacen] visible algo que estaba escondido y [recuperan] la memoria en un país traumatizado por la violencia y la impunidad", ${ }^{49}$ mientras ella "instala el recuerdo en lo sagrado, la historia lo deja al descubierto". 50

Como historia gráfica, Rupay, ${ }^{51}$, de los autores Jesús Cossio, Luis Rosell y Alfredo Villar, cuenta cinco años de la violencia política en Perú. Los escritores expresan que se trata de "la crónica de una tragedia, de una barbarie, de una guerra civil que afectó y enfrentó a los más pobres en este país, ya fueran estos campesinos, soldados o senderistas". 52 La historieta se inicia en Chuschi (región agraria de Ayacucho) y se cierra en el escenario de la localidad serrana de Putis. En principio, un caserío rural habitado por campesinos que fueron arbitrariamente desplazados y despojados de sus fueros patrimoniales y morales durante las décadas del "terror". Rupay muestra cómo estuvieron sometidos a las intimidaciones, vejaciones y torturas constantes, tanto del grupo senderista como de las fuerzas estatales. Cientos de ellos desaparecieron físicamente y sus cuerpos fueron devorados por cerdos. ${ }^{53}$

grupos clandestinos de acuerdo a cada situación y para misiones específicas [...]. El Ejército es jerárquico y un mayor no mueve un dedo si la orden no viene de arriba [...] de bien arriba porque sin decisión política no se mueve nada. [...] eran eso: o-pe-ra-ti-vos. No eran de-ci-so-rios". Umberto Jara, Ojo por ojo: La verdadera historia del grupo Colina (Lima: Página, 2007), 64-7.

45 Ver anexo, fig. 1.

46 Asesor de temas políticos culturales e investigador del Instituto de Estudios Peruanos.

47 Vich, Poéticas del duelo,62-5.

48 Ibid., 66.

49 Ibid., 64.

50 Nora, Les lieux de mémoire, 21.

51 La voz Rupay significa en quechua "fuego, ardor", pues es una "chispa en la pradera la que terminaría incendiando todo Perú” Jesús Cossio, Luis Rossell y Alfredo Villar, Rupay (Lima: Reservoir books, 2016), 19. Recuérdese que el comienzo del caos interno se ubica el 17 de mayo de 1980 al iniciarse con el incendio de las actas electorales por parte del grupo armado de Sendero Luminoso.

52 Ibid., 9.

53 Ibid., 134-6. 
El nombre de la narración iconográfica se toma del vocablo quechua que hace referencia al "ardor" que azotó la nación. Las bandas de senderistas armados por un lado, y, por otro, los militares y policías prorrumpieron en gritos y llamaradas, entre defensas y ataques se apagaron cientos de vidas.

Llama la atención los pocos colores empleados por la historieta, aunque efectivos. El rojo, el blanco (como los colores de la bandera del país y la de Sendero Luminoso) y el negro, que fortalece las sombras y la oscuridad de la noche en algunas microescenas. Como todo cómic, relata en cuadros o viñetas los numerosos sucesos que se vivieron durante aquella época. Las tiras grafican secuencias del ordenamiento interno, de las estrategias de planeamiento, organización y expansión utilizadas por Sendero Luminoso, las respuestas de los bandos políticos y de seguridad del Estado como opositores al caos que esparcía el movimiento, la repercusión de la prensa y, en ella, la exaltación a la barbarie.

El impacto psicosocial tanto individual como colectivo, las inminentes impugnaciones oficialistas que buscaban parar el fortalecimiento y por ende el desarrollo del partido de ideales comunistas. La violencia se replegaba con violencia y, en el medio, quedaba desolada y marginada la población campesina.

La historia exhibe pasajes fuertes, algunos, documentados en la misma viñeta. ${ }^{54}$ Entre ellos, muertes de perros a manos de civiles con cuchillos, a los que se les saca las tripas y se las frota en la cara; vejaciones sexuales a mujeres de diferentes edades; golpes de puños o con elementos; disparos de armas de fuego; torturas, secuestros, ajusticiamiento y muerte a los familiares (padre, madre, hermano, hermanas, hijas) delante de niñas, niños o menores de edad. Estos hechos eran revelados por la prensa, que seguía atenta las noticias de horror y muerte que "quemaban" poco a poco toda parcela lógica o racional. Los recortes de diarios nacionales con titulares sensacionalistas, destacan con adjetivos y exclamaciones los atropellos llevados a cabo por parte de la oficialidad de turno: "Sinchis ${ }^{55}$ azuzaron la matanza ¡Bestias! Asesinaron a 8 periodistas a golpes de hacha, cuchillo y piedras. Al noveno lo crucificaron", 56 o los asaltos sorpresivos que realizaban los llamados "terrucos". Al respecto,

54 Ver anexo, fig.2

55 La voz sinchi, en quechua, significa "duro". Es un grupo oficial del Estado que forma parte de una unidad especializada de la Policía Nacional de Perú, durante el período del "terror", demostraron agresivas políticas militares.

56 Cossio, Rossell y Villar, Rupay, 72. 
alega Rupay, que por "la desconexión vial", 57 la prensa no pudo cubrir todas las tragedias vividas en el país.

Estas manifestaciones simbólicas que se muestran en la ciudad o en las afueras, lo hacen de diferentes formas, ayudan a erradicar las políticas en torno a la negación de lo ocurrido; además, funcionan como hipertexto remitiendo al receptor a la búsqueda del "qué" y del "quién".

\section{3. ¿De qué hay recuerdo? ¿De quién es la memoria?}

Antes del ingreso de un objeto, de un hecho, de un acontecimiento a la memoria, es preciso agregar que existen eslabones de factores previos que son los que suministran los insumos a esta gran cadena. De esta manera, Sergio Gruzsinsky plantea reflexiones acerca de la planificación de individuos visionarios que se fue llevando a cabo a lo largo de los años, en el pretendido intento de imponer un lenguaje estético que deseaba extenderse y legitimarse en épocas que datan desde principio del siglo XVI en México. La voluntad política de ese entonces administra los símbolos que los indígenas debían venerar.

Implicaba pensar no solo en la consumación del "ídolo", sino que había que determinar las consecuencias que esto traería a la sociedad, las repercusiones que emanarían. Para luego ofrecer un culto a la imagen que cobraría efectos pensados previamente o no, sean estos políticos, sociales negativos, como el rechazo y la indiferencia, o positivos, como la admiración y la aceptación colectiva. Como una imagen carece de lenguaje nulo, pues responde a fines intelectuales, simbólicos, religiosos no es de extrañar cómo se generan las guerras (las destrucciones de lo creado anteriormente) antes de que un símbolo nuevo, que tiene el propósito de instaurarse en la comunidad, sea aceptado.

Como enseña Walter Benjamin, no se provee un documento de cultura que no sea a la vez uno de barbarie, y obtiene como resultado lógico introducir la estética en la vida política; retoma a Marinetti quien dice la guerra es bella porque crea nuevas formas arquitectónicas de tanques inmensos, formaciones aéreas geométricas, espirales de humo de los pueblos en llamas". ${ }^{58}$ Para Benjamin, este espectáculo muestra que la población es todavía inmadura al 
no comprender los aparatos técnicos y usarlos contra sí misma, la obra de arte involuciona, ya que desde la contemplación aristotélica ha pasado ahora a gozar de su autodestrucción. ${ }^{59}$

Frente a la natural alienación que produce el estado "estético" del caos, Paul Ricoeur plantea dos interrogantes eje — ¿de qué hay recuerdo?, ¿de quién es la memoria? - que enhebran en buena medida este documento. En primera instancia, la etapa historiográfica de la que se tiene memoria son los 20 años que aproximadamente duró el conflicto interno peruano. La data que subrayan los informes serios, los prólogos a los textos de esta temática, los analistas políticos, los periódicos regionales, también Rupay como inicio del conflicto es el 17 de mayo de 1980, en la localidad de Chuschi, en la provincia de Ayacucho. Considero que es impreciso señalar una fecha exacta del fin del acontecimiento, dado que los "restos", las pérdidas humanas y materiales, las secuelas, que quedaron en la conciencia de los sobrevivientes no se mide en tiempo real, ni mucho menos cronológico.

El pronombre interrogativo quiere saber quién es el sujeto que piensa, necesita conocer el "ser", ya que la memoria es importante para la construcción de la identidad. En épocas de resignificaciones, la categoría "identidad" cumple una función solidaria conmigo mismo y con el "otro", dado que contar los hechos que nos parece que son los más importantes de la narración histórica se relaciona con el "cómo" lo recuerdo, qué zona ilumino más y por qué; en definitiva, la memoria no es otra cosa que la metonimia del sujeto, que conmemora retazos, fragmentos de fragmentos. Es impulsada por diversos mecanismos interiores, pero, cuando estos no son voluntarios, deben activarse desde el exterior. Los dispositivos culturales actúan como espejos sociales, registran y devuelven la imagen proyectada. Así indica Sergio Gruzsinsky que las producciones dan "vida propia a las configuraciones simbólicas y animan el espacio visual [porque] ofrecen un instrumento cómodo: la imagen [...] instantánea [...] esencial para el triunfo" ${ }^{\natural 0}$ de una estrategia de recuperación de las intersubjetividades individuales y colectivas de los hechos relatados. Pues adquiere significaciones distintas "de la que se ve con el ojo". ${ }^{61} \mathrm{El}$ "nuevo" lenguaje territorializa, "extirpa el demonio", 62 ese sitio se transforma en el preámbulo donde se va a

59 Walter Banjamin, Discursos interrumpidos I. (Buenos Aires: Taurus, 1989).

60 Sergio Gruzsinsky, "Los efectos admirables de la imagen barroca”, en La guerra de las imágenes, Sergio Gruzsinsky, 102-59. CDMX: FCE, 1994.

61 Ibid., 18.

62 Ibid., 143. 
erigir el altar, "un lugar cristianizado se vuelve entonces inviolable [...] porque instituye un compromiso tácito", ${ }^{63}$ un imaginario que alguien debe continuar.

La memoria psíquica corporal pertenece a quienes lo experimentaron y vivieron, los nacionales, pero también de los extranjeros, que consideran a la humanización como el devenir de la hominización ${ }^{64}$ y no al revés. Antropológicamente hablando, esta facultad activa va en sentido contrario al aburrimiento y a la pasividad posmoderna, no consiste en una postura de conformismo, porque desarrolla una actividad no pasiva. Como actividad liberadora, en cada momento histórico, la memoria no solo es libre, es privada, se transmuta en el único recodo al que nadie puede invadir, y convive amigablemente con la libertad de conciencia. Ambas permiten el diálogo con "mi" intimidad, y en un contexto de violencia política es cuando más se necesita.

No en vano, en los conflictos bélicos se le teme más a la tortura que a la muerte, porque el agresivo y externo tormento al que "me" someten intenta robar la verdadera sustancia: lo que reside en mí, lo que "soy", mi esencia.

\section{A modo de cierre}

Que sigan existiendo parcelas sociales que se niegan a reconocer los errores producidos en bandos oficialistas como no oficialistas quizá responda al posicionamiento inherente hacia un tipo de saber político que los sujetos consciente o inconscientemente practican. Los discursos estéticos no se pronuncian a favor o en contra de unos u otros, sino que activan las memorias colectivas e individuales y empujan a reflexionar sobre recodos olvidados por muchos e ignorados por las generaciones nuevas.

Los procesos culturales enumerados abordan la preocupación que tienen las generaciones mayores en depositar el recuerdo como legado, debido a que, si no se manifiestan expresiones simbólicas, si el silencio de la cotidianidad contemporánea lo acapara todo, entonces, cabe la posibilidad de que el error humano pueda redoblarse. ${ }^{65}$

Finalmente, quien comunica mediante la obra logra que el espectador se inquiete ante la presencia de una composición estética, pues, el efecto que le produce actúa desde el

63 Ibid., 143

64 Leonardo Polo. "Sobre el origen del hombre: hominización y humanización", Revista de Medicina (Universidad de Navarra, Pamplona) 39 (1994): 41-7.

65 Se alude a las palabras archiconocidas del poeta español Jorge Ruiz de Santayana, "aquellos que olvidan su historia están condenado a repetirla". 
presente, moviliza a la memoria e interviene antes de que acontezca la dilatación absoluta del pasado que es una forma de eliminar la sospecha y extinguir el terror.

“conocer dirija el hacer transformador, esto es, que dirija las acciones, [...] que las dote de sentido [...]"66 durante la composición de los signos estéticos y después de creados pero antes de que acontezca la dilatación absoluta del pasado que es una forma de eliminar la sospecha y extinguir el terror.

66 Polo, 2005, 3. 


\section{Bibliografía}

Arendt, Hannah. La condición humana. Buenos Aires: Paidós, 2009.

Bauman, Zygmunt. La modernidad líquida. Buenos Aires: FCE, 2002.

Benedetti, Mario. "En el gran simulacro". En El olvido está lleno de memoria, Mario Benedetti, 13. Buenos Aires: Sudamericana, 2000.

Benjamin, Walter. La obra de arte en la época de su reproductibilidad técnica. CDMX: Ítaca, 2003.

. Discursos interrumpidos I. Buenos Aires: Taurus, 1989.

Bourdieu, Pierre. "Elementos de una teoría sociológica de la percepción artística". En Sociología del arte, dirigido por José Sazbón, 43-80. Buenos Aires: Nueva Visión, 1971.

Buck, Susan. "Estética y anestésica: Una reconsideración del ensayo sobre la obra de arte en Walter Benjamin".

55-98. http://www.academia.edu/10504242/Est\%C3\%A9tica_y_anest\%C3\%A9tica._Una_revi si\%C3\%B3n_del_ensayo_de_W.Benjamin_sobre_la_obra_de_arte.

Gruzsinsky, Sergio. "Los efectos admirables de la imagen barroca”. En La guerra de las imágenes, Sergio Gruzsinsky, 102-59. CDMX: FCE, 1994.

Jara, Umberto. Ojo por ojo: La veradera historia del grupo Colina. Lima: Página, 2007.

Nora, Pierre. Les lieux de mémoire. Montevideo: Trilce, 2008.

Polo, Leonardo. Quién es el hombre: Un espíritu en el tiempo. Madrid: Rialp, EUNSA,1996.

Polo, Leonardo. "Sobre el origen del hombre: hominización y humanización". Revista de Medicina (Universidad de Navarra, Pamplona) 39 (1994): 41-7.

Ricoeur, Paul. Tiempo y narración I. México: Siglo XXI, 2004.

Cossio, Jesús, Luis Rossell y Alfredo Villar. Rupay. Lima: Reservoir books, 2016.

Sellés, Juan Fernando. “¿Cultura o culturalismo”. En Antropología para inconformes, Juan Fernando Sellés. Madrid: Rialp, 2005.

Sellés, Juan. "Antropología cultural, filosófica y trascendental”. En Antropología para inconformes, Juan Sellés, 170-208. Madrid: Rialp, 2006.

Taussig, Michael. "Culture of Terror-Space of Death. Roger Casement's Putumayo Report and the Explanation of Torture". Comparative Studies in Society and History 26 n.o 3 (julio de 1984): 467-97.

Vargas, Alberto. "Enfoque antropológico a la crisis cultural de occidente”. En La crisis antropológica de occidente y el crecimiento personal, Alberto Vargas, 23-68 (tesis doctoral Universidad de Navarra, Pamplona).

Vich, Víctor. Poéticas del duelo. Lima: IEP, 2015. 


\section{Anexo}

Figura 1

Diez cantutas en Cieneguilla, de Ricardo Wiesse

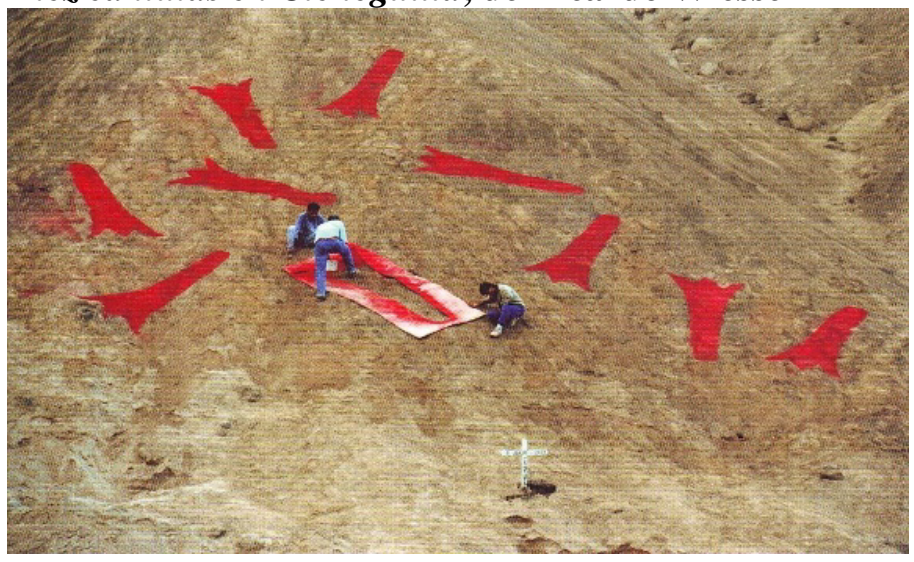

Fuente: Daniel, "Cantuta, Ricardo Wiesse, en el Paradero Habana de Micromuseo". laseleccioninutil.blogspot.pe, 26 de agosto de 2008. http://laseleccioninutil.blogspot.pe/2008/08/cantuta-ricardowiesse-en-el-paradero.html

Figura 2

Escenas de Rupay de Cossio, Rosell y Villar

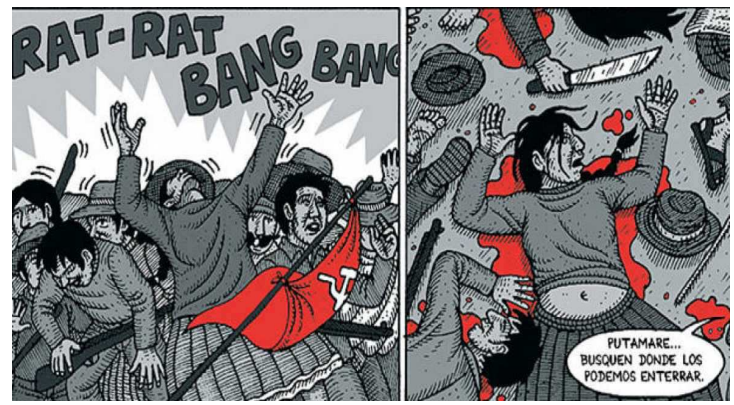

Fuente:_ Jesús Jiménez y Víctor Gómez, "Rupay: Un cómic en busca de la verdad", www.rtve.es, 3 de diciembre de 2009. http://www.rtve.es/noticias/20091203/rupay-comic-buscaverdad/304177.shtml 
VISTA DE

MUACACION

OLTURA

Figura 3

Campesinos de Huaraccopata

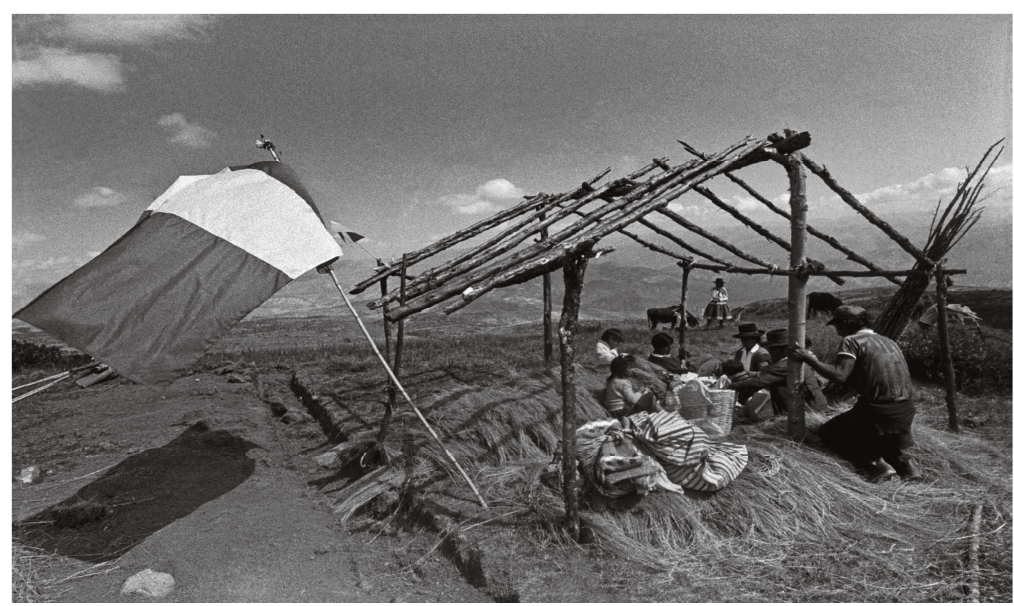

Fuente: Yuyanapaq. Para recordar, idehpucp.pucp.edu.pe/yuyanapaq/ 